\title{
Comparative study between conventional fistulectomy and SLOFT in cases of low fistula in ano
}

\author{
Shalabh Gupta ${ }^{1, *}$, Apoorv Goel ${ }^{2}$, Varun Pathak ${ }^{3}$, T. S Bhagat ${ }^{4}$, Prakhar Garg $^{5}$ \\ ${ }^{1}$ Professor and Head, ${ }^{2,5}$ Assistant Professor, ${ }^{3}$ Post Graduate Student, ${ }^{4}$ Professor, ${ }^{1-4}$ Dept. of Surgery, Santosh Medical College \& \\ Hospital, Ghaziabad, Uttar Pradesh, India \\ *Corresponding Author: \\ Email: drshalabhgupta@gmail.com
}

\begin{abstract}
Introduction: Fistula in ano is a common anorectal disorder requiring surgical intervention. It is associated with high recurrence rate and post-operative complications. In this study we have analysed and compare results of a newer technique for low anal fistula SLOFT with conventional Fistulectomy.

Aims and Objective: To compare Submucosal Ligation of Fistula Tract (SLOFT) with conventional fistulectomy in patients of low anal fistula by analysing various intra-operative factors and post-operative outcome.

Materials and Methods: An interventional study carried out at Santosh Medical College and Hospitals, Ghaziabad from January 2017 to October 2018. This study included 60 Patients of low anal fistula which were divided into two groups of 30 patients each. Group I was offered Conventional Fistulectomy \& Group II underwent SLOFT.

Result and Observations: Fistula in ano is commonly seen in middle aged males. There is no significant difference in duration of surgery between SLOFT and Fistulectomy. However post-operative complications, pain (measured by VAS scoring system), wound healing and early return to work was significantly better in patients who underwent SLOFT.

Conclusion: SLOFT has significant advantage over convention fistulectomy in terms of post-operative pain, wound healing, early return to work and cosmetic outcome.
\end{abstract}

Keywords: Fistula in ano, Low anal fistula, SLOFT (Submucosal ligation of fistula tract), LIFT (Ligation of intersphincteric fistula tract), Fistulectomy.

\section{Introduction}

A fistula is defined as an abnormal communication between two epithelial surfaces. Anal fistula is a communication between the anorectal canal and the perianal skin that is lined with granulation tissue. The fistula may harbour chronic infection, which may discharge continuously or intermittently through the opening on to the skin. Intermittent discharge is usually caused by cyclical accumulation of an abscess with associated discomfort and pain before some relief from discharge, which is followed by further accumulation. ${ }^{1}$ In the most severe cases, faecal material may also pass through fistula in ano and cause soiling of underwear and skin irritation. The abnormal communication of the lower gastrointestinal system with the perianal region is due to a cryptoglandular infection. ${ }^{2}$ It is believed that the anal crypts become blocked by inspissated debris or stool. As a result, an infection develops at the anal glands, which extends in a path of least resistance, forming an abscess in the inter-sphincteric space leading to the development of a fistula in about one third of patients. It commonly occurs in healthy subjects with cryptoglandular infection as most widely accepted theory. ${ }^{1,2}$ Fistula in ano is classified according to the Park's classification. ${ }^{3}$ Chronic illness like tuberculosis, Crohn's Disease and Malignancy may cause multiple fistulous tracts, recurrent and nonhealing fistula in ano. Magnetic resonance imaging (MRI), Fistulogram, Ultrasound or Transrectal
Ultrasonogram (TRUS) can be helpful in diagnosing high and complex anal fistula. ${ }^{4}$

The treatment of choice for anal fistula is surgery. Various surgical procedures have been described for anal fistula. The aim of surgery should be low recurrence, complete healing, early recovery and no incontinence. ${ }^{1,5}$ Choice of surgical procedure depends upon the type of fistula. Simple and low anal fistula can be managed with fistulectomy or fistulotomy. ${ }^{5}$ But high fistula or complex one requires multiple sessions, setoning or rectal advancement flaps. ${ }^{6}$ Newer techniques like Ligation of intersphincteric fistula tract (LIFT), Video assisted anal fistula treatment (VAAFT), Fibrin glue and radiofrequency ablation have been described in literature too. ${ }^{7-9}$ Complex fistula with faecal discharge may require temporary diversion colostomy initially.

In this study we have described a new procedure Sub-mucosal ligation of fistula tract (SLOFT) which is a modification of LIFT and compared it with conventional fistulectomy in cases of low anal fistula. ${ }^{10}$

\section{Aims and Objective}

To compare SLOFT with conventional fistulectomy in patients of low anal fistula by analysing various intra-operative factors and post-operative outcome in terms of pain, wound healing, recurrence, early return to work and cosmetic outcome. 


\section{Materials and Methods}

An interventional study carried out at Santosh Medical College and Hospitals, Ghaziabad from January 2017 to October 2018. This study included 60 Patients of low anal fistula which were randomly divided into two groups of 30 patients each. Group I was offered Conventional Fistulectomy \& Group II underwent SLOFT. Patients to SLOFT group were informed about the new technique and formal consent was taken. Patients with high complex fistula, recurrent fistulas or concomitant haemorrhoids / anal fissure/rectal prolapse were excluded from the study. Patients underwent necessary pre-operative investigations followed by formal pre-anaesthetic evaluation. MRI or TRUS was done in few selected cases only when indicated. All patients were evaluated for various intra-operative factors and post-operative outcome and data were analysed using IBN statistical package for social sciences (SPSS) version 17.0. Chisquare test and student's t test were used for comparison of data between two groups. P value of < 0.05 was considered significant. Pain was measured as continuous variable using visual analogue scale (VAS, a 0-10 cm scale). Cosmetic outcome was assessed by an experienced surgeon of another unit on the basis of examination of scar seen in the OPD at an interval of $1^{\text {st }}, 4^{\text {th }}$ and $8^{\text {th }}$ week. The surgery in both the groups was performed by a general surgeon having more than 20 years of experience in anorectal surgery.

Technique: SLOFT was performed under SA (Spinal Anaesthesia) with patient in lithotomy position. Digital rectal examination with gentle anal dilatation was done to identify internal opening. External opening was identified and weak methylene blue dye was pushed to see the internal opening. Tract was identified with a help of a pliable copper probe (Fig. 1). A mucosal incision was given 0.5 to $1 \mathrm{~cm}$ away from the internal opening over the tract. The tract was identified over the probe and dissected all around in the submucosal plane (Fig. 2). The tract was ligated with Polyglactin 910, 1-0 suture after withdrawing the probe and then divided (Fig. 3). The external opening was gently excised along with distal end of tract by making a small incision over the skin and sent for histopathology. The mucosal and skin incisions were closed (Fig. 4). A betadine pack was placed in anal canal. Patients are routinely advised post operatively regarding warm baths, cleansing the area, oral diclofenac medication for pain relief, and stool softener. Patients were followed weekly for the first month and then fortnightly for a minimum duration of 3 months, and on each occasion examined for healing, abscess, recurrence, stenosis, cosmetic outcome and incontinence.

Conventional Fistulectomy was done by identifying the tract using a copper probe and then excising it completely upto the anal mucosa and raw area was left open. Patients were followed weekly for the first month and then fortnightly for a minimum duration of 3 months, and on each occasion examined for healing, abscess, recurrence, stenosis, cosmetic outcome and incontinence.

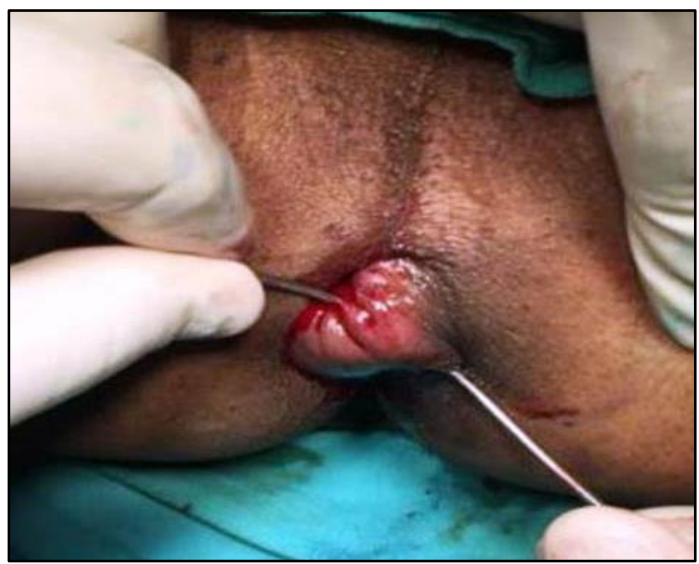

Fig. 1: Tract identification with the help of a pliable copper probe

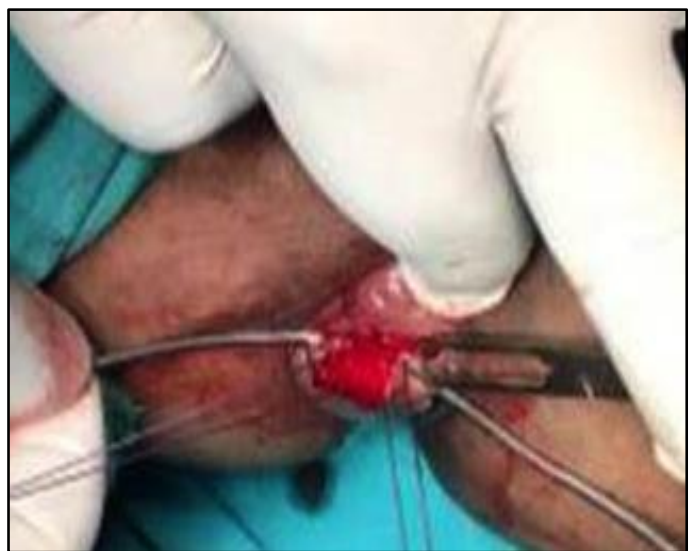

Fig. 2: The tract was identified over the probe and dissected all around in the submucosal plane

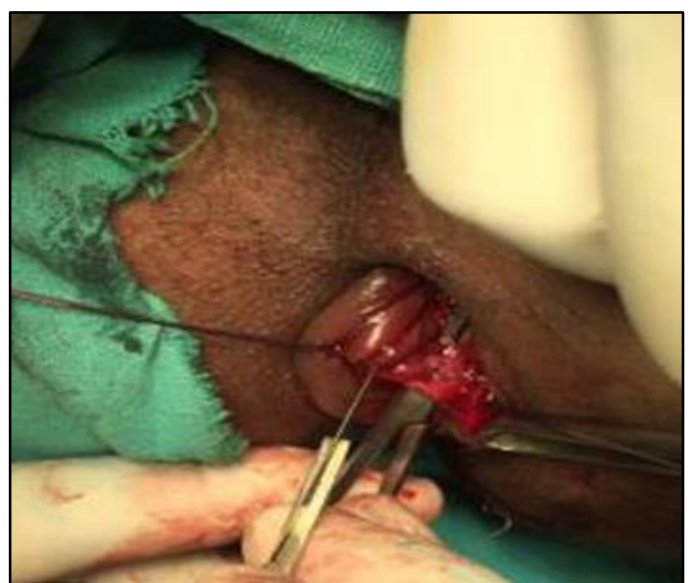

Fig. 3: Tract ligation with Polyglactin 910, 1-0 suture after withdrawing the probe and then divided 


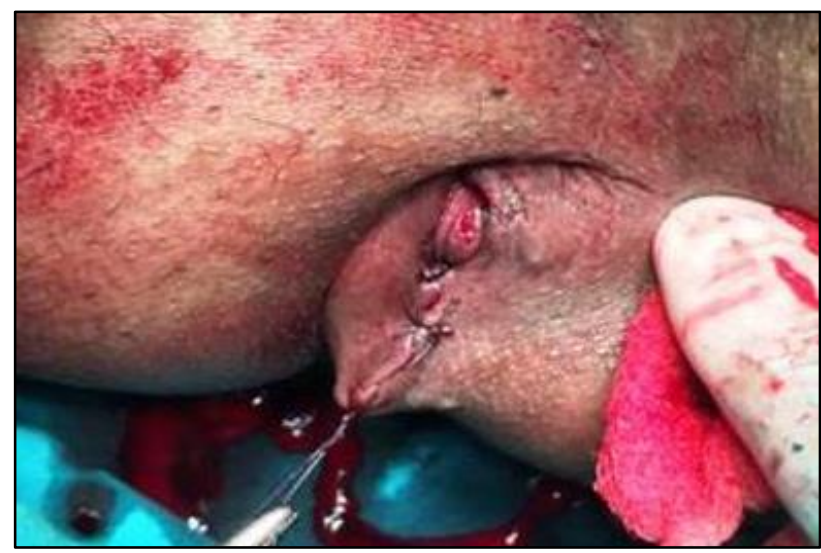

Fig. 4: The mucosal and skin incisions closed

Table 1: Comparative analysis of SLOFT with Fistulectomy on the basis of various intra-operative and postoperative factors

\begin{tabular}{|c|c|c|c|c|}
\hline S. No. & $\begin{array}{l}\text { Intra-operative \& Post- } \\
\text { operative Factors }\end{array}$ & $\begin{array}{l}\text { Conventional } \\
\text { Fistulectomy }\end{array}$ & SLOFT & $\mathbf{P}$ - value \\
\hline 1 & Mean age (Years) & $35.53 \pm 7.46$ & $33.46 \pm 7.15$ & NS \\
\hline 2 & $\begin{array}{l}\text { Mean duration of surgery } \\
\text { (Minutes) }\end{array}$ & $43 \pm 6$ & $46 \pm 5$ & NS \\
\hline 3 & $\begin{array}{l}\text { Intra-operative complications / } \\
\text { Difficulties }\end{array}$ & Nil & Nil & \\
\hline 4 & Conversion to fistulectomy & - & Nil & \\
\hline 5 & $\begin{array}{l}\text { Mean duration of wound } \\
\text { healing (days) }\end{array}$ & $32 \pm 4$ & $11 \pm 2$ & $<0.001 \mathrm{HS}$ \\
\hline 6 & $\begin{array}{l}\text { Mean duration of return to work } \\
\text { (days) }\end{array}$ & $16 \pm 2$ & $7 \pm 1$ & $<0.001 \mathrm{HS}$ \\
\hline 7 & Wound infection / Abscess & 2 & 1 & NS \\
\hline 8 & Incontinence & 1 & Nil & NS \\
\hline 9 & Recurrence & Nil & Nil & \\
\hline \multirow[t]{4}{*}{10} & \multicolumn{4}{|c|}{ Cosmetic outcome (At $8^{\text {th }}$ Week) } \\
\hline & Poor & $6(20 \%)$ & 0 & $<0.001$ \\
\hline & Average & $16(53.3 \%)$ & $5(16.7 \%)$ & $<0.001$ \\
\hline & Good & $8(26.7 \%)$ & $25(83.4 \%)$ & $<0.001$ \\
\hline
\end{tabular}

NS - Non-Significant,

HS - Highly Significant

Table 2: Comparative analysis of post-operative pain using Visual Analogue Scoring (VAS)

\begin{tabular}{|c|c|c|c|c|}
\hline Sl. No. & VAS (0- 10) & $\begin{array}{c}\text { Conventional } \\
\text { Fistulectomy }\end{array}$ & SLOFT & P-value \\
\hline 1 & 24 Hrs. (Day 1) & $5.87 \pm 0.43$ & $3.73 \pm 0.58$ & $<0.001$ (HS) \\
\hline 2 & 48 Hrs. (Day 2) & $5.67 \pm 0.45$ & $3.10 \pm 0.55$ & $<0.001$ (HS) \\
\hline 3 & Day 7 & $1.30 \pm 0.47$ & $1.00 \pm 0.0$ & $<0.001$ (HS) \\
\hline
\end{tabular}

HS - Highly Significant

\section{Observations and Results}

Out of 60 patients 51 were males. There were 28 (93.3\%) and $23(76.67 \%)$ males in group I and II respectively. The mean age of the patients was $35.53 \pm$ 7.46 years and $33.46 \pm 7.15$ years in group I \& in group II respectively (Table 2). Majority of patients in both groups $(53.3 \%$ in group I and $66.7 \%$ in group II) presented with persistent pus discharge from perianal region and at least one third patients in each group had a prior history of perianal abscess. External opening was located posteriorly in $80 \%$ of patients in group I and $87.3 \%$ in group II respectively. None of the patients in both groups were lost to follow up.

Average duration of surgery for fistulectomy (Group I) was $43.30 \pm 6.09$ minutes and for SLOFT (Group II) was $46.47 \pm 5.25$ minutes. There was no significant difference in the duration of surgery in both the groups (Table 1) there were no intra-operative complications / difficulty in both the groups and there was no conversion to conventional fistulectomy of 
patients who underwent SLOFT (Table 1). Wound healing was significantly delayed in group I (31.87 \pm 3.61 days) when compared with group II (11.03 \pm 1.61 days) and early return to work was significantly better in patients who underwent SLOFT (16.30 \pm 1.64 days in group I and $6.67 \pm 0.92$ days in group II) (Table 1). 3 patients in group I and 1 patient in group II had wound infection in post-operative period and 1 patient in group I developed incontinence. However there was no recurrence in both the groups (Table 1).

Post-operative pain assessed on basis of VAS at 24hrs, $48 \mathrm{hrs}$ and day 7 was significantly less in SLOFT group (Table 2). Cosmetic outcome was assessed subjectively and it was significantly better in SLOFT group at the end of $8^{\text {th }}$ week (Table 1 ).

\section{Discussion}

The aim of anal fistula surgery is to eradicate perianal sepsis and achieve healing of the fistula, while preserving anal continence. The dilemma is that the more radical the surgery, the greater is the risk of subsequent anal incontinence, delayed wound healing and prolong bed rest. ${ }^{1,5}$ The various surgical techniques have been described like fistulectomy, fistulotomy, seton, plug, advancement flaps, LIFT and VAAFT. Surgical techniques such as fistulectomy, fistulotomy and cutting seton treatment have good results for healing without recurrence of the fistula, but incontinence and delayed healing are major concerns in post-operative period. ${ }^{5}$ LIFT has advantage of lesser recurrence and decreased morbidity in terms of wound healing and incontinence but technically more demanding specially in high and complex fistula. ${ }^{8}$ VAAFT has got better visualisation of tract and same advantages as LIFT but availability is limited and cost is high. ${ }^{9}$

In this study we have described a fairly new technique SLOFT for low anal fistula which is a modification of LIFT and technically easier to perform, cost effective and having advantage of low recurrence, early healing, preserved continence, less pain, early return to work and better cosmetic outcome. ${ }^{10}$

In this study majority of patients were male with ratio of $6: 1$ and mean age was $34.64 \pm 5.3$ years which is comparable to the previous studies. ${ }^{4,5}$ Almost $25 \%$ of patients in each group had a history of prior perianal abscess. ${ }^{2}$ Since there was no significant difference in duration of surgery for both groups we can say SLOFT is a technically easy to learn and perform. Statistically significant difference was seen in wound healing as it was $11.03 \pm 1.61$ days after SLOFT and $31.87 \pm 3.61$ days for fistulectomy. Similarly patients after SLOFT were able to resume their routine work after $6.67 \pm 0.92$ days whereas it took $16.30 \pm 1.64$ days for fistulectomy patients. Post-operative pain was significantly less in SLOFT group. Similar results were seen in the study done by DU Pathak et al on SLOFT in 2014. ${ }^{10}$ Cosmetic outcome after SLOFT was good and there was no recurrence or incontinence.

SLOFT is easy, safe and effective technique for low anal fistula with early healing and good cosmetic outcome and no morbidity in terms of recurrence and incontinence.

\section{Conclusion}

The aim of anal fistula surgery is low recurrence, early recovery and minimal incontinence. SLOFT is safe, technically easy and cost-effective. It has all these advantages and offers early recovery, less pain, good cosmetic outcome and minimal complications. However, recurrence rates may vary since minimum period of follow up was taken as 3 months.

\section{Conflicts of Interest: None.}

\section{References}

1. Parks AG. Pathogenesis and treatment of fistuila-inano. Br Med J. 1961;1(5224):463-69.

2. Ramanujam PS, Prasad ML, Abcarian H, Tan AB. Perianal abscesses and fistulas. A study of 1023 patients. Dis Colon Rectum. 1984;27(9):593-97

3. Parks AG, Gordon PH, Hardcastle JD: A classification of fistula-in-ano. Br J Surg. 1976;63(1):1-12.

4. Buchanan GN, Halligan S, Bartram CI, Williams AB, Tarroni D, Cohen CR. Clinical examination, endosonography and MR imaging in preoperative assessment of fistula in ano: comparison with outcome-based reference standard. Radiol 2004;233(3):674-81.

5. Malik AI, Nelson RL. Surgical management of anal fistulae: a systemic review. Colorectal $\mathrm{Di}$. 2008;10:420-30.

6. Hyman N. Endoanal advancement flap repair for complex anorectal fistulas. Am J Surg. 1999;178:33740.

7. Song KH. New Techniques for Treating an Anal Fistula. J Korean Soc Coloproctol. 2012;28(1):7-12.

8. Rojanasakul A. LIFT procedure: a simplified technique for fistulain-Ano. Tech Coloproctol. 2009;13:237-40.

9. Meinero P, Mori L. Video-assisted anal fistula treatment (VAAFT): A novel procedure for treating complex anal fistula. Tech Coloproctol. 2011;15(4):417-22.

10. D.U. Pathak, V. Agrawal, V.K. Taneja. Submucosal Ligation of Fistula Tract (SLOFT) for ano-rectal fistula: An effective and easy technique. Ambulatory Surg. 2014;20(3):42-43. 